\title{
Chromatographic Determination of Hydrocarbon Waxes in Tobacco Leaf and Smoke*
}

\author{
by O. T. Chortyk, R. F. Severson and H. C. Higman \\ Tobacco Laboratory, Agricultural Research Service, United States Department of Agriculture, \\ Athens, Georgia, U.S.A.
}

\section{INTRODUCTION}

The occurrence and identity of long-chain, aliphatic hydrocarbons or paraffins in tobacco leaf and smoke have been studied $(1-7)$. Initial methods differentiated only between normal and branched paraffins. Thus, it was established that about one quarter of the paraffins of smoke were branched (8), and that the ratio of odd to even isomers in leaf varied from $3: 1$ to $11: 1$, depending upon leaf variety (9). Gradual refinements in methodology, such as gas dhromatography on glass capillary columns (10) and the combination of gas chromatography with mass spectrometry $(\mathrm{xI}, 12)$, definitively established the presence and proportions of iso, normal, and anteiso paraffins.

The advent of the smoking and health controversy focused considerable interest on the paraffins and the other constituents of the hexane extract of tobacco as precursors of some of the biologically active polynuclear aromatic hydrocarbons (PAH) of smoke. High-temperature pyrolytic experiments on the paraffin dotriacontane indicated that it could be a precursor for PAH $(13,14)$. Precursors of the PAH of smoke have been extensively discussed $(15,16)$. More recently, it has been shown that ${ }^{14} \mathrm{C}$-labeled dotriacontane, sprayed onto cigarette tobacco, is not a precursor for benzo(a)pyrene (BaP), but instead distils almost unchanged into the smoke $(17,18)$. However, selected constituents of the hexane extract, such as phytol and $\beta$-sitosterol have been shown to be relatively effective high temperature precursors of $\mathrm{BaP}$ (19). More significantly, it was shown that pyrolysis of the total hexane extract yielded nearly two thirds of the BaP obtained in tobacco pyrolysis (2o). However, a hexane extract of tobacco also contains various terpenoids, carotenoids, sterols, esters and glycerides components, which, upon pyrolysis, are more likely to produce the PAH of smoke. It is essential that this question of PAH precursors be settled.

Recently, a large quantity of petroleum ether extract of flue-cured tobacco was fractionated to provide material for a pyrolytic study to answer the above question. As previously observed, petroleum ether (PE) eluted white waxes from a column of silicic acid in a

- Rectired for gublicarion: 12th Marh, 1975. chromatographic fractionation of the extract. It was noted that these waxes were very similar to paraffins obtained in chromatographic separations of the neutrals of cigarette smoke condensate.

Consequently, it was decided to study the paraffin transfer from leaf to smoke under actual smoking conditions, as a preliminary step to the pyrolytic studies. A representative cigarette tobacco mixture and a fue-cured tobacco with a high wax content were to be examined. In comparing the wax contents of different tobacco samples, we used the standard method by Bacot (21). However, the wax precipitates so obtained apparently were contaminated with other tobacco constituents and did not resemble the clean, white material that we had obtained by chromatography. Consequently, it was necessary to develop a chromatographic method for leaf paraffins.

The details of the chromatographic procedure for leaf and smoke paraffins are described here. The transfer of paraffins from the tobacco of reference cigarettes to smoke is detailed. Subsequently, the paraffins were analyzed by gas chromatography-mass spectrometry (GC-MS) and leaf waxes were compared to material obtained by the Bacot method and to smoke condensate paraffins. The use of a high temperature GC support and the analytical results on the distribution of parafin isomers are also described.

\section{METHODS AND MATERIALS}

\section{Tobacco Extraction}

Dried, ground (32 mesh) flue-cured tobacco (North Carolina, 197x) was extracted with glass-distilled $30-60^{\circ} \mathrm{C}$ petroleum ether (PE) (Burdick and Jackson Laboratories**, Muskegon, Midhigan) in a Soxhlet apparatus, for 24 hours. The PE extract was filtered, the PE removed on a totary evaporator, and the residue dried in an oven at $95^{\circ} \mathrm{C}$ for I hour. The flue-cured tobacco yielded about $6.7 \mathrm{~g}$ of extract per $100 \mathrm{~g}$ of dried tobacco. The extracted tobacco (marc) was also dried. The total weights of PE extract and marc were added to calculate the true, dry weight of unextracted

\footnotetext{
4* Mention of commercizl items does not imply their endorsement by the Department over similar products not mentioned.
} 
tobacco. For experiments to determine the precision of the column dhromatographic method, 1008 samples of tobacco were extracted and each dilute PE extract was divided volumetrically into 8 or to samples. Tobacco from too University of Kentudky, type xRx, reference cigarettes (22) was dried to yield 97.098 of material. The tobacco was extracted as above to yield $3.89 \mathrm{~g}$ of $\mathrm{PE}$ extract.

\section{Column Chromatography}

Silicic acid (too mesh, Mallinckrodt) was washed with nanograde methyl alcohol and air-dried in an oven at $150^{\circ} \mathrm{C}$ for 18 hours. The PE extracts of tobacco were redissolved in a minimum amount of $\mathrm{PE}$ with warming by a hot-air gun and applied to the top of a silicic acid. (SA) column by disposable pipettes: Small volumes of solvent were used to rinse the extract flask. Collection of the first fraction, F-I, was begun upon application of the PE extract to the top of the column. A ratio of $\mathrm{i} g$ of $\mathrm{PE}$ extract to $100 \mathrm{~g} \mathrm{SA}$ yielded the paraffins in the first $200 \mathrm{ml}$ of $\mathrm{PE}$ eluate (F-x). Thus, for example, the paraffins in $0.80 \mathrm{~g}$ of a PE extract, from about 12.5 8 of tobacco, when diromatographed on $80 \mathrm{~g}$ of $S A$, would elute in the first $160 \mathrm{ml}$ of $\mathrm{PE}$ ( $\pm 8 \mathrm{ml}$ depending on proper packing of the column and volume of extract solution applied). Similarly, for a larger sample of $16.4 \mathrm{~g}$ of PE extract chromatographed on $1640 \mathrm{~g}$ of SA, the paraffins eluted completely in the first $3200 \mathrm{ml}$. To determine an accurate cut-off for paraffins, about $80 \%$ of $F-I$ should be collected first, then the remainder in 5-10 ml portions in small beakers. Evaporation of PE shows where elution of the white waxes stops and where the clear, oily neophytadiene fraction (F-2) starts. For the comparative experiments, fraction yield data are summarized in Table 1 and Fig. 2.

\section{Chromatography of Smoke Condensate Paraffins}

The cigarette smoke condensate (CSC) from 450 cigarettes was collected in a dry-ice trap under standard conditions: the cigarettes were preconditioned at $60 \%$ relative humidity for 48 hours and smoked in a 3o-port Borgwaldt smoking machine to a butt length of $23 \mathrm{~mm}$ at $1 \mathrm{puff} / \mathrm{min}$ with a 2-second puff duration and a puff volume of $35 \mathrm{ml}$. The neutral portion of the CSC was obtained as previously described (23). Chromatography of the neutrals $(2.19 \mathrm{~g})$. on $100 \mathrm{~g}$ of $\mathrm{SA}$ and elution with $800 \mathrm{ml}$ of PE yielded a total wax fraction of $0.274 \mathrm{~g}$.

\section{Gas Chromatography (GC)}

Waxes were analyzed on a Hewlett-Packard Model 5750 gas chromatograph, equipped with flame ionization detectors. A $10^{\prime} \times 1 / 8{ }^{\prime \prime}$ stainless steel column of $5 \%$ Dexsil 300 GC on $80 / 100$ mesh Chromosorb W/AW was heated at $80^{\circ} \mathrm{C}$ for $5 \mathrm{~min}$, programmed to $325^{\circ} \mathrm{C}$ at $4^{\%} / \mathrm{min}$, and held at $325^{\circ} \mathrm{C}$ for $30 \mathrm{~min}$. The flow rate was $50 \mathrm{ml} / \mathrm{min}$, with injector and detector tempera- tures at $325^{\circ} \mathrm{C}$. Detector response data from 23 normal paraffins $\left(\mathrm{C},-\mathrm{C}_{s}\right)$ were plotted vs. relative retention time (relative to $C_{36}$ ). Response factors, used to calculate weight yields for all wax components except neophytadiene, were obtained from the plot. The neophytadiene, used to calculate its response data, was obtained by preparative GC from total wax fractions. Known weights of the Cst internal standard were added to all samples analyzed. Mass spectral data were obtained from a high resolution DuPont Model 21-492 mass spectrometer connected to a Varian Model 1400 gas dhromatograph. The chromatographic column and conditions were the same as described above.

\section{RESULTS AND DISCUSSION}

The application of column dromatography to paraffin analysis is: not a new idea. Paraffins have been chromatographed on alumina (24) and on silicia gel $(25-27)$. We have extensively used silicic acid column chromatography in the fractionation of cigarette smoke condensate neutrals for bioassay (23). We have adapted the technique to obtain clean samples of leaf or smoke paraffins. In this manner, crystallizations from selected solvents, urea complexing; or chromatography on silver-nitrate-impregnated supports were avoided. More importantly, no sample was lost due to various precipitation techniques.

Initially, $1 \mathrm{~g}$ samples of PE extract of flue-cured tobacco were dromatographed on $50 \mathrm{~g}$ columns of methanol-washed, activated SA. Elution with $x 1$ of PE yielded a semi-solid, white wax. However, our wax yields were about $50 \%$ lower, by weight, when compared to those obtained by the Bacot method. Thinlayer chromatography and GC showed that only about $65-70 \%$ of the waxes, obtained in the dromatographic fraction, were true paraffins; the remainder was mostly neophytadiene. Therefore, it was necessary to separate the paraffins from the neophytadiene. This was accomplished by collecting small fractions of the total PE eluate to determine the cut-off point for paraffin elution. Also, the ratio of PE extract to SA was yaried to determine the best ratio for a good separation of neophytadiene from the waxes. It was shown that dromatography of $1 \mathrm{~g}$ of PE extract on $100 \mathrm{~g}$ of SA yielded waxes in the first $200 \mathrm{ml}$ of PE eluate (Fig. 1) and neophytadiene in the next $300 \mathrm{ml}$. The proportion of $x: 100: 200$ was also applicable to smaller weights of PE extracts of tobacco, with the same separations of neophytadiene. Generally, 1o $g$ samples of tobacco were conveniently extracted and analyzed for wax contents. This would yield wax samples weighing about $40 \mathrm{mg}$ for a $0.4 \%$ waxcontaining tobacco. The percent paraffin content was calculated based upon yields of dried PE extracts and extracted tobacco (marc). However, percent of total hydrocarbons may be more relevant to the correlation with smoke $\mathrm{PAH}$, than the percent paraffins. 
Figure 1. Recommended paraffin method.

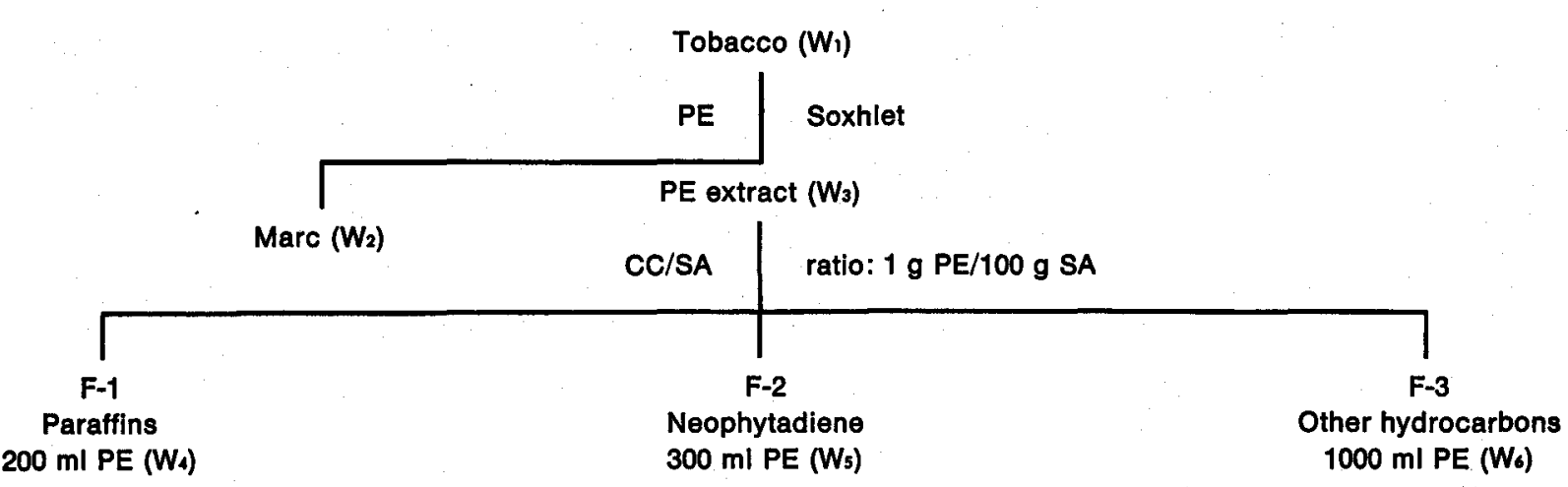

$\begin{aligned} \% \text { Paraffins } & =\frac{W_{4}}{W_{2}+W_{3}} \times 100 \\ \% \text { Total hydrocarbons } & =\frac{W_{4}+W_{5}+W_{6}}{W_{2}+W_{3}} \times 100\end{aligned}$

Subsequently, our method was compared to that of the standard Bacot wax method. For a selected fluecured tobacco sample, the percentage of waxes obtained by our method, for 8 runs, was $0.38 \%$. For the same sample, the Bacot method yielded $0.75 \%$ (Table 1 ). (The Bacot method essentially involves dissolving the PE extract of tobacco in hot ethyl alcohol and subsequently cooling it in ice-water. The precipitated waxes are filtered off and redissolved in ether. The ether solution is then evaporated and the weight of the waxes determined.) GC was employed to determine the composition and volatility of the respective wax precipitates. GC showed that more than $95 \%$ of the paraffins obtained by our method were GC volatile, while only $35 \%$ of the waxes from the Bacot method were volatile. This indicated that the true values for waxes for the identical sample were $0.36 \%$ by the paraffin method and only $0.25 \%$ by the Bacot method.

Therefore, it was necessary to determine why the Bacot method was, in reality, yielding low quantities of paraffins. Accordingly, half of a PE extract was subjected to our paraffin method (Fig. 2). GC showed that $92 \%$ of the paraffins were volatile and the paraffin value was $35.9 \mathrm{mg}$. The other half of the extract was subjected to the Bacot procedure. The alcohol solution, which should not have contained any waxes, was also subjected to column chromatography and GC and was found to contain $13.2 \mathrm{mg}$ of waxes. The precipitated waxes from the Bacot method were divided and one half was subjected to GC directly, while the other half was subjected to SA column chromatography. The total amount of paraffins for that experiment was $23.4 \mathrm{mg}$. Thus, the total amount of waxes recovered in the Bacot procedure was $36.6 \mathrm{mg}$. When the value of $36.6 \mathrm{mg}$ was taken as $100 \%$, the paraffin method, which yielded $35.9 \mathrm{mg}$, produced $98 \%$ of the waxes in one fraction. From this experiment, it was apparent that about $1 / 3$ of the paraffins had not been precipitated in the Bacot method and that $2 / 3$ of the "wax precipitate" was actually non-paraffin material.

Paraffins were characterized by GC-MS techniques. GC separations were performed successfully on the relatively new liquid phase, Dexsil $300 \mathrm{GC}$, a carboranesilicone polymer that is reported to be stable in packed columns to $450^{\circ} \mathrm{C}$ (28). A gas chromatogram

Table 1. Comparative yields for the recommended paraffin method vs. the Bacot wax method.

\begin{tabular}{|c|c|}
\hline \multirow[t]{2}{*}{ Procedure } & $\begin{array}{l}\text { PARAFFIN METHOD } \\
\text { PE EXTRACT }\end{array}$ \\
\hline & CC/SA $\underbrace{\substack{1: 100 \\
\text { ratio } \\
(F-1)}}_{\text {PARAFFINS }}$ \\
\hline $\begin{array}{l}\% \text { Waxes } \\
\% \text { Range } \\
\text { GC volatiles } \\
\% \text { True waxes }\end{array}$ & $\begin{array}{c}0.38 \text { (8 runs) } \\
0.30-0.45 \\
95 \%+\text { average } \\
0.95 \times 0.38=0.36 \\
(100 \%)\end{array}$ \\
\hline
\end{tabular}

BACOT METHOD (21)

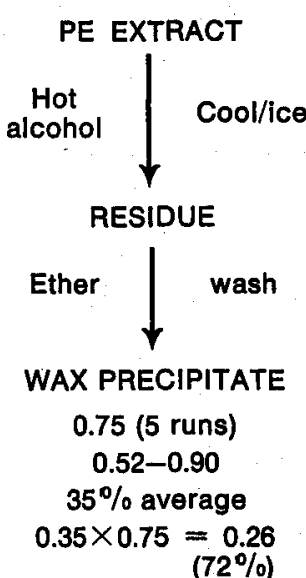


Figure 2. Distribution of paraffins in Bacot wax mothod.

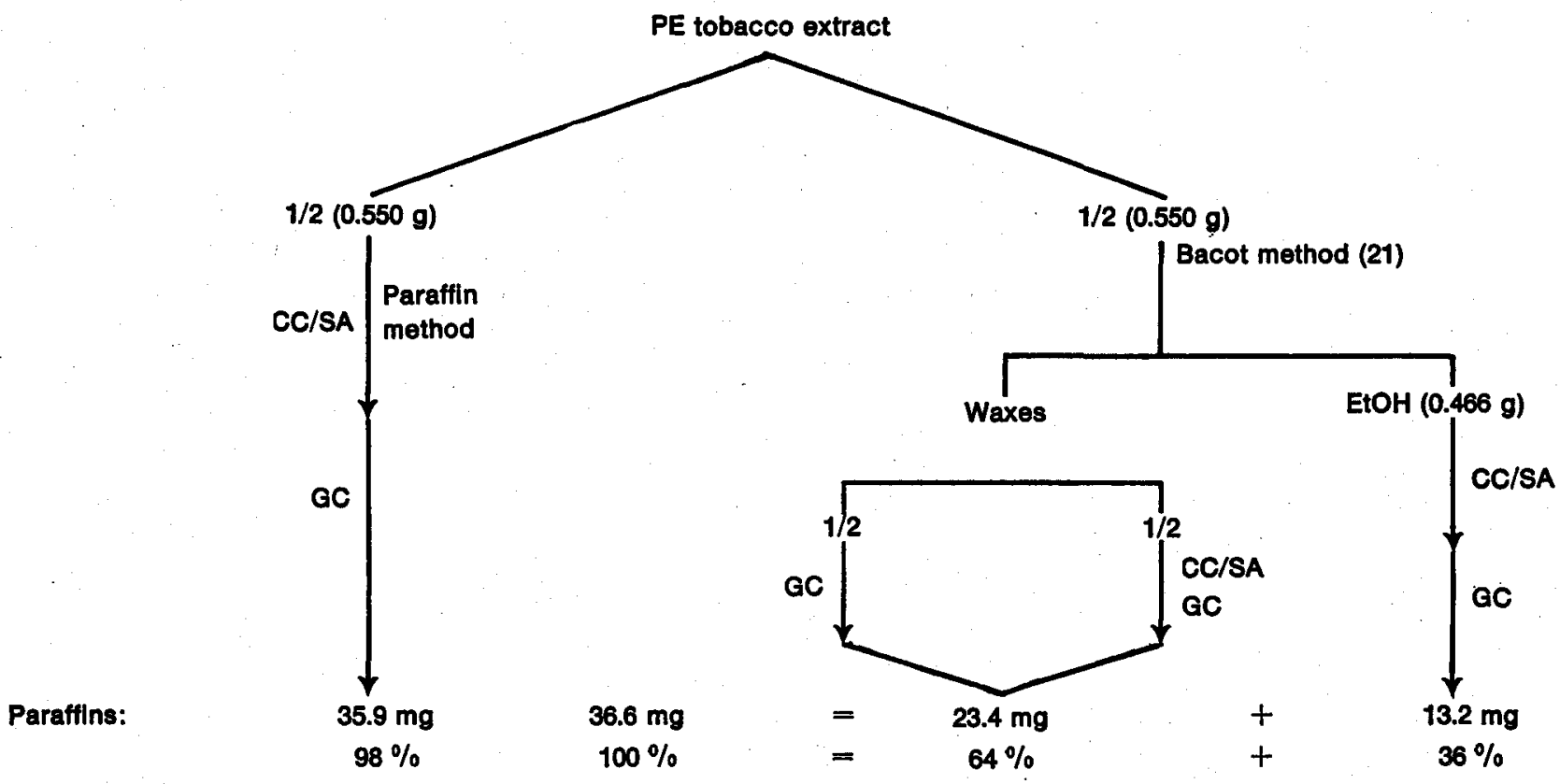

for a SA refined paraffin fraction (F-I) of flue-cured tobacco is shown in Fig. 3. For the flue-cured tobacco extract that we were examining, F-I represented about $70 \%$ of the total PE eluate from the column. The paraffins are identified by carbon chain length and $\mathrm{n}$, a, and $\mathrm{i}$ refer to normal, anteiso, and iso compounds. A typical chromatogram for the next SA fraction (F-2) is shown in Fig. 4. Most of this fraction was neophytadiene (about 90-95\%). A small quantity of paraffins was sometimes present in F-2, but this was usually not more than $5 \%$ of the total waxes. The last SA fraction (F-3) was less than $5 \%$ of the PE eluate from the SA column, and was not characterized. (This fraction was later shown to contain many hydrocarbon impurities from the glass-distilled $\mathrm{PE}$ that we were using.)

The compositions of the paraffins for flue-cured and $I R I$ cigarette tobaccos, and for smoke condensate from $I R_{I}$ reference cigarettes are presented in Table 2. The predominant waxes of leaf, both for the flue-cured and the IRI reference cigarette tobaccos, ranged from $\mathrm{C}_{27}$ to about $\mathrm{C}_{35}$; whereas, the waxes of the smoke condensate ranged from about $\mathrm{C}_{10}$ to $\mathrm{C}_{35}$. As already known, the major paraffins of smoke and leaf are in the $\mathrm{C}_{28}$ to $\mathrm{C}_{3 s}$ region. The normal paraffins were identified by GC retention times and mass spectral data; anteiso and iso isomers were identified by mass spectral data only.

Figure 3. Gas chromatogram of paraffin fraction F-1 of flue-cured tobacco.

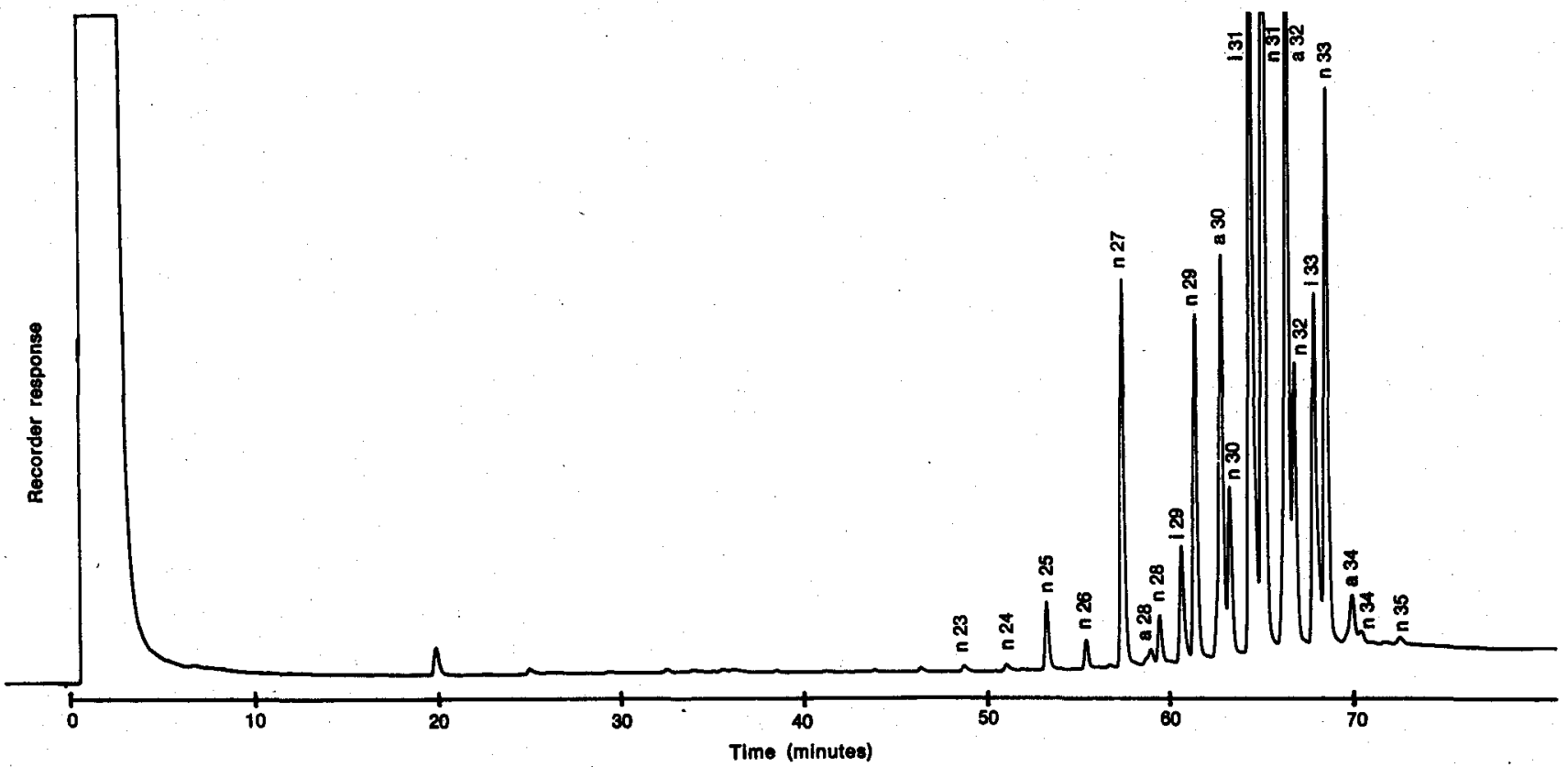


Table 2. Percent composition of paraffin tractionsa.

\begin{tabular}{|c|c|c|c|c|c|c|c|}
\hline \multirow{2}{*}{ Compound } & \multicolumn{2}{|c|}{ Identiflcation } & \multirow{2}{*}{$\begin{array}{c}1 R 1 \\
\text { tobacco }\end{array}$} & \multirow{2}{*}{$\begin{array}{l}\text { 1R1 } \\
\mathrm{CSC}\end{array}$} & \multirow{2}{*}{$\begin{array}{c}\text { Flue-cured } \\
\text { tobacco }\end{array}$} & \multirow{2}{*}{$\begin{array}{c}\text { Literature } \\
\text { valuesb }\end{array}$} & \multirow{2}{*}{$\mathbf{R}_{\mathbf{T}^{\mathrm{c}}}$} \\
\hline & GC-MS & MS & & & & & \\
\hline$n-C 13$ & + & & - & 0.21 & - & & 0.259 \\
\hline$n-C 14$ & + & & - & 0.40 & - & & 0.310 \\
\hline$n-C 15$ & + & & - & 0.76 & - & & 0.358 \\
\hline$n-c 16$ & + & & 0.06 & 0.20 & 0.06 & & 0.402 \\
\hline$n-c \quad 17$ & + & & 0.02 & 0.39 & 0.02 & & 0.446 \\
\hline$n-c 18$ & + & & 0.23 & 0.56 & 0.07 & & 0.487 \\
\hline$n-C \quad 19$ & + & & - & 1.86 & - & & 0.527 \\
\hline$n-c 20$ & + & & - & 0.83 & - & & 0.567 \\
\hline$n-C 21$ & + & & - & 0.65 & - & & 0.598 \\
\hline$n-C 22$ & + & & 0.08 & 1.02 & 0.04 & & 0.632 \\
\hline$n-c 23$ & + & & 0.08 & 0.79 & 0.02 & & 0.663 \\
\hline$n-c 24$ & + & & - & 1.88 & 0.04 & & 0.695 \\
\hline$n-c 25$ & + & & 0.76 & 2.48 & 0.10 & & 0.725 \\
\hline$n-c 26$ & + & & 0.33 & 2.25 & 0.42 & & 0.754 \\
\hline$n-C 27$ & + & & 5.67 & 5.42 & 6.56 & 7.73 & 0.781 \\
\hline$a-C 28$ & & + & 0.27 & 0.22 & 0.40 . & 0.13 & 0.801 \\
\hline$n-C 28$ & + & & 0.61 & 2.24 & 0.74 & 0.89 & 0.808 \\
\hline i-C 29 & & + & 1.82 & 1.38 & 2.03 & 1.24 & 0.825 \\
\hline$n-c 29$ & + & & 6.16 & 5.39 & 5.41 & 6.72 & 0.835 \\
\hline$a-c 30$ & & + & 6.46 & 4.13 & 7.30 & 5.65 & 0.854 \\
\hline$n-C 30$ & + & & 2.17 & 2.82 & 2.49 & 3.16 & 0.860 \\
\hline $1-C 31$ & - & + & 12.81 & 8.24 & 14.19 & 10.92 & 0.877 \\
\hline$n-C 31$ & + & & 23.81 & 16.62 & 21.31 & 26.30 & 0.885 \\
\hline$a-c 32$ & & + & 12.89 & 9.74 & 15.25 & 13.02 & 0.902 \\
\hline$n-C \quad 32$ & + & & 3.85 & 3.65 & 4.23 & 4.88 & 0.908 \\
\hline$i-C 33$ & & + & 6.26 & 4.05 & 6.96 & 15.62 & 0.923 \\
\hline$n-C 33$ & + & & 12.81 & 7.52 & 10.00 & 10.77 & 0.933 \\
\hline$a-c 34$ & & + & 1.14 & 0.69 & 1.21 & 1.15 & 0.949 \\
\hline$n-C \quad 34$ & + & & 0.33 & 0.34 & 0.28 & & 0.955 \\
\hline I-C 35 & & + & - & - & 0.16 & & 0.966 \\
\hline$n-c 35$ & + & & 0.43 & 0.44 & 0.28 & & 0.976 \\
\hline
\end{tabular}

a: Based on total amount of GC volatile material in fraction, excluding neophytadiene.

b: Commercial cigarette tobacco blend (11).

c: Retention times, relative to $n-C 36=1.00$

For comparative purposes, literature values for waxes from a commercial blend of cigarette tobacco (11) are included in Table 2. The values compare well to our results for a flue-cured tobacco. The former method (11) for GC analysis required pre-extraction of the wax fraction with concentrated sulfuric acid to remove unsaturated components, followed by separation of the n-alkenes from the branched isomers on molecular sieve.

The percentage of GC-volatile materials and amounts identified for the three waxes are given in Table 3 . We identified more than $99 \%$ of the material from the flue-cured and $1 R_{1}$ cigarette tobaccos. However, for smoke condensate from the $I R_{1}$ reference cigarettes, about $73 \%$ of the components could be identified. This was due to the fact that only about $80 \%$ of the wax fraction was GC-volatile.

Finally, the transfer from leaf to smoke of the total waxes or total hydrocarbons was determined. The total waxes would contain the paraffins, neophytadiene, and other hydrocarbons. On a one-gram basis, IRI reference cigarette tobacco contained $2.57 \mathrm{mg}$ of waxes; whereas, condensate obtained from this $I R I$ reference cigarette tobacco contained only $1.12 \mathrm{mg}$ of waxes. This indicated that more than $56 \%$ of the material was not transferred to the mainstream smoke. Some of it was trapped in the cigarette butt, some thermally degraded, and some lost into the sidestream smoke. It was also convenient to calculate the transfer of neophytadiene. It was shown that about $40 \%$ of the neophytadiene of leaf tobacco appears to be "destroyed" on smoking. Thus, a PE wax fraction of

Table 3. Percent composition of petroleum ether fractions.

\begin{tabular}{l|r|r|c}
\cline { 2 - 4 } & $\begin{array}{c}\text { Flue- } \\
\text { cured } \\
\text { tobacco }\end{array}$ & $\begin{array}{c}\text { 1R1 } \\
\text { tobacco }\end{array}$ & $\begin{array}{c}\text { tR1 } \\
\text { cigarette } \\
\text { smoke } \\
\text { conden- } \\
\text { sate }\end{array}$ \\
\hline GC volatile material & 100 & 100 & 80 \\
GC volatile material identified & 99 & 99 & 91 \\
Total identified & 99 & 99 & 73 \\
\hline
\end{tabular}




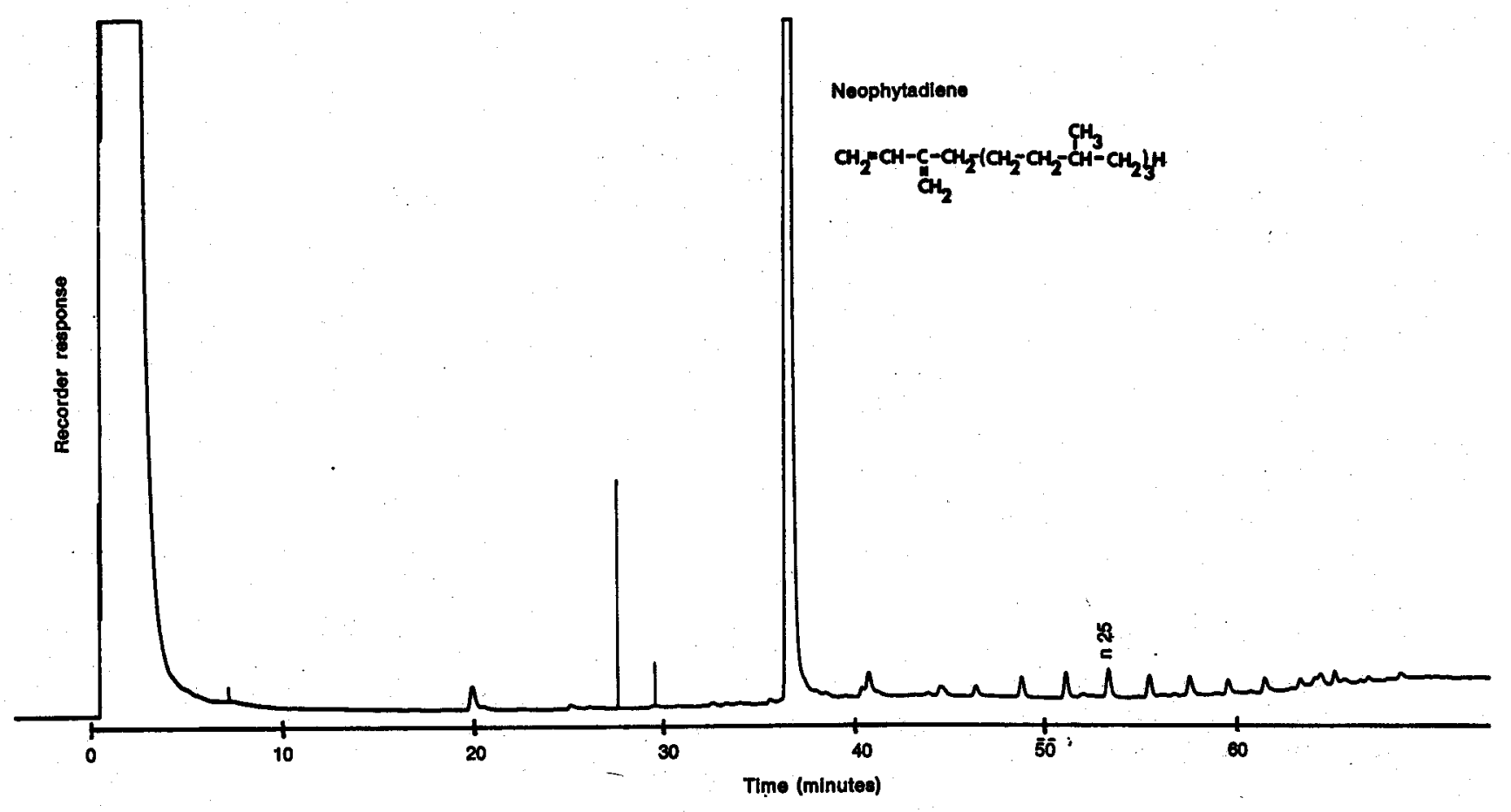

IRI cigarettes contained $49 \%$ neophytadiene, while the IRI smoke condensate wax fraction only contained $29 \%$. Thus, neophytadiene was either partitioned into the sidestream more than the paraffins, or, much more likely, underwent pyrolytic decomposition because of its multiple branching and double bonds.

The following conclusions were reached upon analysis of the GC results. The major paraffins ( $1 \%$ or more) of flue-cured tobacco or IRI reference cigarette tobacco are the $C_{27}$ to $C_{35}$ isomers. The major paraffins in the smoke of IRI reference cigarettes are the $C_{10}$ to $C_{35}$ compounds. That is, more of the lower paraffins occur in smoke. For normal and iso paraffins, odd-numbered isomers predominate: that is, $C_{27}, C_{29}, C_{31}$, and $C_{33}$ occur as the normal and iso paraffins. For anteiso paraffins in leaf or smoke, even-numbered isomers predominate: that is, $C_{28}, C_{30}$, and $C_{32}$ occur as the anteiso and the normal paraffin. Leaf paraffins are transferred to smoke paraffins in the same relative proportions. In other words, the ratio among the constituents in leaf paraffins is almost identical to the ratio among the constituents in smoke paraffins. This suggests that paraffins undergo little pyrolytic degradation. Although, there is apparently considerable loss to sidestream smoke, or non-transfer of waxes, as mentioned. In studies with radioactively labeled dotriacontane, it was shown that $49 \%$ of the activity was found in the sidestream smoke, presumably as unchanged dotriacontane (17).

In summary, we have concluded that leaf paraffins can be easily isolated from a petroleum ether extract by column chromatography on activated silicic acid and elution with petroleum ether in a definite substrate to solvent ratio. Smoke paraffins can also be separated from cigarette smoke condensate neutrals by column chromatography. Paraffins can be resolved and identified by GC on Dexsil 300 GC and their identities confirmed by GC-MS. The chromatographic paraffin method yields a cleaner wax or paraffin -residue which is suitable for direct GC analysis. The method gives a truer picture of the paraffin content of tobacco leaf or smoke condensate.

\section{SUMMARY}

Paraffins of tobacco leaf were separated by column chromatography on silicic acid. Leaf paraffins were fractionated from other wax constituents by chromatography in a definite sample to substrate to solvent ratio. The developed method was used to evaluate the transfer of paraffins and neophytadiene from leaf to smoke in a reference cigarette. Gas chromatographic separations were performed on a high-temperature liquid phase. Gas chromatography in conjunction with mass spectrometry was used to determine the paraffin composition of a representative flue-cured tobacco, a reference cigarette tobacco, and smoke condensate. It was concluded that paraffins were probably transferred to smoke relatively unchanged, while neophytadiene underwent some pyrolytic decomposition.

\section{ZUSAMMENFASSUNG}

Mittels Säulenchromatographie auf Kieselsäure wurden die Paraffine des Tabakblattes fraktioniert. Sie wurden von anderen Wachsen des Tabaks durch Chromatographie in einem bestimmten Verhältnis von Probe zu Substrat zu Lösungsmittel getrennt. Die entwickelte 
Methode wurde benutzt, um bei einer Bezugscigarette den Ubergang von Paraffinen und von Neophytadien vom Blatt in den Rauch zu untersuchen. Die gaschromatographischen Trennungen wurden an einer hochtemperaturbeständigen Phase durchgeführt. Gaschromatographie in Verbindung mit Massenspektrometrie diente zur Bestimmung der Paraffinzusammensetzung eines repräsentativen " "flue-cured"-Tabaks, eines Bezugscigarettentabaks und von Rauchkondensat. Es wurde gefolgert, daß Paraffine wahrscheinlich verhältnismäßig unverändert in den Rauch übergehen, während Neophytadien einige pyrolytische Umsetzungen durchmacht.

\section{RESUME}

Les paraffines de feuille de tabac ont été séparées sur colonne chromatographique d'acide silicique. Les paraffines des feuilles ont été séparées d'autres constituants cireux par chromatographie dans des conditions définies quant au rapport échantillon/substrat/solvant. Cette méthode a été utilisée pour évaluer le transfert des paraffines et du néophytadiène de la feuille dans la fumée d'une cigarette de référence. La séparation par drromatographie en phase gazeuse a été réalisée sur une phase liquide à haute température. La chromatographie gazeuse couplée au spectromètre de masse a permis de déterminer la composition paraffinique d'un tabac "flue-cured" représentatif, d'un tabac à cigarette référence, et de condensat de fumée. La conclusion de ces expériences est que les paraffines sont probablement transférées avec peu d'altérations, alors que le néophytadiène subit une certaine décomposition pyrolytique.

\section{REFERENCES}

I. Stedman, R. L.: Chem. Revs. 68 (1968) 153, and references therein.

2. Johnston, R. L., and L. A. Jones: Anal. Chem. 40 (11) (1968) 1728.

3. Mashkovtsev, M. F., and S. S. Chkheidze: Tr. Gruz. Inst. Subtrop. Khoz. 12 (1968) 349.

4. Chang, N.: Diss. Abstr. Int. B 32 (11) (1972) 6263.

5. Anastasov, A., V. P. Pisklov and I. G. Mokhnachev: Bulg. Tiutiun 13 (11) (1968) 27.

6. Grabulovski, T.: Tutun 19 (11/12) (1969) 353.

7. Pisklov, V. P., and I. G. Mokhnachev: Izv. Vyssh. Udheb. Zaved., Piskch. Tekhnol. 3 (1970) 51.

8. Mokhnachev, I. G., and V. P. Pisklov: Ber. Inst. Tabakforsch. Dresden 16 (1969) 59.
9. Mokhnachev, I. G., and V. P. Pisklov: Rast. Resur. 6 (3) (1970) 423.

10. Carugno, N., and S. Rossi: Beitr. Tabakforsch. 3 (1966) 555.

11. Mold, J. D., R. K. Stevens, R. E. Means and J. M. Ruth: Biochem. 2 (1963) 605.

12. Gelpi, E., and J. Oro: J. Chromatogr. Sci. 8 (4) (1970) 210.

13. Badger, G. M., J. K. Donnelly and T. M. Spottswood: Aust. J. Chem. 18 (1966) 1249.

14. Schlotzhauer, W. S., I. Schmeltz and S. F. Osman: Chem. and Ind. 1970, 1377.

15. Wynder, E. L., and D. Hoffmann: Tobacco and Tobacco Smoke; Academic Press, New York, N. Y., 1967, Chapter 7 .

16. Schlotzhauer, W. S., E. B. Higman and I. Schmeltz: The chemistry of tobacco and tobacco smoke; Plenum Press, New York - London, 1972, 65.

77. Jenkins, R. W., R. H. Newman, R. D. Carpenter and T. S. Osdene: Beitr. Tabakforsch. 5 (1970) 295.

18. Jenkins, R. W., R. H. Newman, M. D. Edmonds and T. S. Osdene: Beitr. Tabakforsch. 7 (1973) 154.

19. Schlotzhauer, W. S., and I. Schmeltz: Beitr. Tabakforsch. 5 (1969) 5 .

20. Schlotzhauer, W. S., and I. Schmeltz: Beitr. Tabakforsch. 4 (1968) 176.

21. Bacot, A. N.: USDA Tech. Bul. 1225, 115, 1960.

22. Atkinson, W. O.: Production of sample cigarettes for tobacco and health research; University of Kentucky Tobacco and Health Conference, 1970, Lexington, Ky., USA.

23. Chamberlain, W. J., and R. L. Stedman: The chemistry of tobacco and tobacco smoke; Plenum Press, New York - London, 1972, 99 .

24. Mokhnachev, I. G., V. P. Pisklov and L. A. Dulan: Appl. Biochem. Microbiol. 3 (1967) 186.

25. Rodgman, A. J.: Org. Chem. 24 (1959) 1916.

26. Nooner, D. W., and J. Oro: Geohim. Cosmochim. Acta. 31 (1967) 1359.

27. Enzell, C. R., A. Rosengren and I. Wahlberg: Tob. Sci. 13 (1969) 127.

28. Analabs, Inc. Research Notes: 14 (1), April 1974; Analabs, Inc, North Haven, Conn., USA.

The authors' address:

Tobacco Laboratory, Agricultural Research Service, United States Department of Agriculture, Athens, Georgia, 30604, USA. 